\title{
A PERTINÊNCIA DA ABORDAGEM DIREITO E POLÍTICAS PÚBLICAS AO ESTUDO DA POLÍTICA URBANA NO BRASIL: $O$ EXEMPLO DA PESQUISA SOBRE AS VIAS URBANAS E SUA FUNÇÃO SOCIAL
}

\author{
THE RELEVANCE OF THE LAW AND PUBLIC POLICY \\ APPROACH TO THE STUDY OF URBAN POLICY IN BRAZIL: \\ THE EXAMPLE OF RESEARCH ON URBAN ROADS AND THEIR \\ SOCIAL FUNCTION
}

FREDERICO HADDAD ${ }^{1}$

Resumo: A abordagem Direito e Políticas Públicas tem contribuído muito à pesquisa jurídica sobre diversos programas governamentais. Em uma agenda de balanço da abordagem - que passa por compreender questões para as quais é mais frutífera, pensar ferramentas de comparabilidade entre os estudos, estabelecer referências de pesquisa, consolidar estratégias de tratamento das interfaces com os campos do direito e identificar potencialidades - este artigo visa destacar a pertinência da abordagem ao estudo da política urbana. Foi dividido em três partes: primeiro, retomam-se as características do método; depois, aborda-se a política urbana no Brasil, sublinhando-se seus pontos de convergência com as estratégias da abordagem; enfim, apresenta-se a contribuição da abordagem à pesquisa jurídica sobre as vias urbanas e sua função social, desenvolvida na dissertação de mestrado do autor. Concluiu-se que os principais pontos de convergência com a abordagem se devem ao fato de a política urbana: (i) objetivar a garantia de direitos sociais; (ii) ser caracterizada pela transversalidade em relação às áreas de governo; (iii) depender da operação de um arranjo institucional complexo; (iv) pressupor interpretação sistemática de normas de diversas áreas; (v) ter sua consecução dificultada por entraves jurídicos; (vi) materializar realçado conflito distributivo; (vii) ilustrar o descompasso entre prescrições normativas e realidade.

Palavras-Chave: Abordagem Direito e Políticas Públicas; Políticas Públicas; Política Urbana; Vias Urbanas; Função Social.

1 Mestre em Direito do Estado pela Faculdade de Direito da USP. Lattes: http://lattes.cnpq.br/4105863716744475. Contato: fredericohaddad@gmail.com. 
ABstract: The Law and Public Policies' approach has contributed to the legal research on various policies. Considering an agenda of assessment - that comprehends the matters for which it is most productive, thinking tools to compare studies, establishing references of research, consolidating strategies to deal with the interfaces' approach on the fields of the law and identifying potentialities - the present article highlight the relevance of the approach on the study of urban policy. It was divided in three sections: first, the characteristics of the approach are resumed; next, considerations on urban policy in Brazil are made, stressing the converging aspects of its nature and the approach's strategies; lastly, the contribution of the approach to the legal research on urban roads' social function is presented, further developed in the master's dissertation of the author. Finally, it was noted that the converging aspects with the approach are due to the fact that urban policy: (i) intents to ensure social rights; (ii) is characterized by transversality; (iii) depends on a complex institutional arrangement; (iv) assumes a systematic interpretation of legal norms; (v) has its achievement hampered by legal barriers; (vi) materializes a significative distributive conflict; (vii) illustrates mismatch between the legal commands and reality.

Keywords: Law and Public Policies' Approach; Public Policies; Urban Policy; Urban Roads; Social Function.

\section{INTRODUÇÃO}

Impulsionada, entre outros fatores, por um período histórico que, embora breve, foi marcado por uma tentativa concreta de materialização do Estado Social prometido pela Constituição Federal de 1988 (“CF/1988”), a pesquisa jurídica brasileira vem se dedicando crescentemente ao campo das políticas públicas, sob as mais diversas óticas. Vale notar que, por si só, trata-se de boa notícia, já que isso pode significar o início de um rompimento com os escassos incentivos tradicionalmente oferecidos pelo ensino jurídico do país à pesquisa desse campo (COUTINHO, 2012, p. 3).

Entre as diferentes metodologias empregadas para o estudo das políticas públicas sob a perspectiva do direito, a abordagem direito e políticas públicas ("DPP") tem se destacado pela fertilidade, contribuindo, a partir de aplicações de ênfases e configurações variadas, para o aprofundamento da compreensão sobre uma vasta gama de temas atinentes aos programas de ação governamental e sua conformação jurídica. Contudo, a mesma versatilidade que permitiu, até aqui, a produção de resultados de pesquisa relevantes e, não raro, inovadores nesse amplo 
campo de estudo, impõe, adiante, o desafio de sistematização coletiva sobre os resultados parciais, os limites e as possibilidades da própria abordagem.

Trata-se, assim, de uma agenda de "balanço", que passa, entre outras coisas, por: (i) compreender as questões governamentais para as quais a abordagem DPP se mostra mais (ou menos) frutífera; (ii) pensar novas ferramentas metodológicas que refinem a comparabilidade entre os estudos que dela se valeram; (iii) estabelecer referências de pesquisa compartilhadas passíveis de generalização; (iv) consolidar estratégias de tratamento das interfaces da abordagem com os diferentes campos do direito; e, ainda, (v) identificar, a partir dos resultados obtidos, as principais potencialidades atestadas, bem como as possíveis insuficiências do método. ${ }^{2}$ Tudo isso, sem prejuízo de que, em paralelo a essa agenda emergente, a abordagem DPP siga, sem interrupção, servindo à ampliação e ao aprofundamento da pesquisa de temas específicos atinentes ao campo das políticas públicas sob as lentes jurídicas. Para além de não se excluírem entre si, podendo caminhar concomitantemente, essas frentes de pesquisa podem e devem se retroalimentar e se enriquecer mutuamente, ensejando constante diálogo.

No contexto do estabelecimento dessa agenda de meta-análise, justifica-se que aqueles que já a utilizaram revisitem as premissas teóricas da abordagem e o percurso de sua aplicação ao tema estudado. Intuitivamente, essa parece ser uma das formas mais efetivas de concretizar o trabalho de sistematização desse conhecimento coletivamente acumulado, servindo, no agregado, a um movimento de constante consolidação, aperfeiçoamento e atualização do método e de sua aplicação.

Exatamente esse será o esforço do presente artigo, a partir da reflexão sobre a pertinência da abordagem DPP ao estudo da política urbana. Tal reflexão será dividida em três partes: (i) em primeiro lugar, sem qualquer pretensão de fazer uma descrição exaustiva, serão retomadas as principais características da abordagem DPP; (ii) em seguida, serão feitas considerações sobre a política urbana no Brasil, sublinhando-se a forma como as características da abordagem DPP, antes tratadas, contribuem ao seu estudo; (iii) por fim, a título de ilustração concreta da pertinência defendida em abstrato, será apresentada a contribuição da abordagem à pesquisa jurídica sobre as vias urbanas e sua função social, desenvolvida na dissertação de mestrado do autor (HADDAD, 2019).

\section{ABORDAGEM DPP: UMA SÍNTESE PARCIAL}

Essa primeira seção do artigo se presta a sintetizar as principais características da abordagem DPP, a fim de retomá-las, adiante, para sustentar sua pertinência ao estudo das diversas políticas públicas que compõem a política urbana. Além de não se pretender exaustiva, essa descrição sintética, justamente em vista do seu

${ }^{2}$ Sobre isso, ver o artigo de Bucci (2019). 
propósito, terá certo viés: a apresentação dos principais traços da abordagem privilegiará a ênfase aos aspectos que serão retomados na seção seguinte.

A abordagem DPP é, antes de tudo, um método que tem como foco compreender o direito "em ação" nas políticas públicas, possibilitando a integração dos estudiosos do direito a este campo multidisciplinar (BUCCI; COUTINHO, 2017). Conforme explicam os Professores Maria Paula Dallari Bucci e Diogo R. Coutinho (2017, p. 316), “a ênfase [da abordagem DPP] está na concepção, implementação e funcionamento dos arranjos institucionais, expressões particulares de organização da ação governamental, em função de objetivos determinados", cuja consecução depende determinantemente de engrenagens jurídicas.

Os mesmos autores destacam três premissas importantes adotadas pela abordagem DPP (BUCCI; COUTINHO, 2017, p. 317-318).

Em primeiro lugar, pressupõe-se que, sem prejuízo da necessária distinção entre a política pública e os elementos jurídicos que a estruturam, a compreensão da política pública passa por reconhecer os aspectos jurídicos que lhe são intrínsecos e as diversas funções desempenhadas pelo direito no processo de sua formulação e execução: normatização dos objetivos a serem perseguidos; apontamento dos instrumentos a serem utilizados em sua consecução; criação de canais de participação social e legitimação democrática; e, com grande ênfase, a estruturação de arranjos institucionais voltados à coordenação de processos e à atribuição de responsabilidades aos agentes envolvidos (BUCCI; COUTINHO, 2017, p. 317). Nesse último caso, destaca-se a conformação da política pública, pelas normas, processos e instituições jurídicas, no tocante aos modos de interação dos atores institucionais envolvidos em sua elaboração e execução, bem como aos atributos do desenho institucional que a sustenta - atinentes ao chamado plano mesoinstitucional (BUCCI, 2013).

Em segundo lugar, entende-se que os arranjos institucionais são mais bem apreendidos e avaliados a partir da consideração de seus "traços jurídicos exteriores", que disciplinam "a composição, o funcionamento e os limites de mudanças de tais arranjos, os quais, por sua vez, disciplinam o emprego da capacidade estatal de implementar programas de governo" (BUCCI; COUTINHO, 2017, p. 317-318). Em síntese, o fato de os arranjos que conformam os programas de ação governamental e sua implementação serem moldados e operados juridicamente coloca a perspectiva do direito, ao lado de outras, em posição privilegiada à observação das políticas públicas.

Por fim, a abordagem DPP tem como premissa a possibilidade (e a necessidade) de aperfeiçoamento das políticas públicas e seus arranjos também a partir de uma perspectiva jurídica, contribuindo para conferir-lhes maior eficácia, legitimidade e efetividade. Aqui, tem-se um desdobramento da apreensão do direito "em ação" 
nas políticas públicas, que imbui o estudioso do direito de um olhar projetado para o futuro, que integra o núcleo da proposta da abordagem DP.

Essa última premissa enumerada - relativa à possibilidade de aperfeiçoamento das políticas públicas - deriva, então, para um dos três elementos relevantes explicados por Bucci (2017) quando da descrição das estratégias desse método de análise. Trata-se justamente da visão prospectiva, entendida como "o direcionamento da capacidade analítica a propor cenários para o futuro" e "traçar estratégicas, com base nesse tipo de análise" (2017, p. 38-39). Ao lado da visão prospectiva, a autora destaca como dois outros elementos relevantes à abordagem DPP, a perspectiva do Poder Executivo e a consideração da escala da ação governamental.

Como sustenta Bucci (2017, p. 35), no sistema presidencialista, o Poder Executivo tanto dá a direção política do governo como gere a máquina administrativa que impulsiona a formulação e execução dos programas de ação governamental, configurando-se como o grande protagonista da iniciativa e conformação das políticas públicas. Da estratégia metodológica de adotar, por tais razões, a perspectiva do Poder Executivo derivam dois traços distintivos importantes desta em relação às abordagens tradicionalmente adotadas pelo direito na análise de políticas públicas: (i) a atenção permanente às normas de cunho regulamentar (frequentemente subestimadas nas análises jurídicas) e às implicações que trazem, sobretudo, à implementação das políticas públicas tal qual originalmente concebidas; e (ii) a consideração de uma dimensão processual ampla e transversal na produção de políticas públicas, que extrapola o processo legislativo, envolvendo, entre outros, o processo de planejamento, o processo orçamentário, o processo administrativo e assim por diante.

O terceiro elemento, que diz respeito à questão da escala dos programas de ação governamental, refere-se à necessidade de dimensionar, do ponto de vista quantitativo, o problema social a que a política pública se dirige, utilizando-se de metodologias consolidadas em áreas como ciência política e economia para realizar "comparações temporais e geográficas em face do público demandante, do alvo ideal de um programa, de experiências similares no contexto internacional, e assim por diante", a fim de subsidiar a compreensão da dimensão coletiva de alguns direitos (BUCCI, 2017, p. 37).

Esse terceiro elemento ilustra outra característica da abordagem DPP, atinente à sua aptidão para um olhar multidisciplinar sobre as políticas públicas, valendose de referências de diversos campos do conhecimento para enriquecer o olhar sobre as políticas públicas, sem se afastar das lentes jurídicas que lhe são próprias. A multidisciplinaridade que a reveste não se reflete apenas na relação do estudo jurídico das políticas públicas com outras esferas do conhecimento, de modo que a abordagem DPP também propicia o necessário estabelecimento de conexões e interfaces entre as diferentes áreas do direito. No limite, tem-se como consequência natural da utilização da abordagem o constante desnudamento de entraves 
oferecidos pelo próprio direito - amplamente compreendido - à implementação efetiva das políticas públicas.

Por fim, para os objetivos deste artigo, cabe destacar que a abordagem DPP, conformada por todas essas premissas e estratégias metodológicas, tem como um de seus principais méritos o fato de permitir que sejam colocados lado a lado fatores políticos e jurídicos, examinando, de modo estruturado, as influências recíprocas entre ambos no processo de elaboração e execução das políticas públicas. Pode-se dizer, nesse sentido, que a compreensão estruturada e sistemática das tensões existentes entre o político e o jurídico e a capacidade de comunicá-las estão entre os principais ativos da abordagem, oferecendo condições favoráveis para a identificação, a discussão e o aperfeiçoamento das relações estabelecidas entre as políticas públicas e o arcabouço jurídico que as conforma e operacionaliza (BUCCI; COUTINHO, 2017, p. 314).

\section{A POLÍTICA URBANA NO BRASIL E A PERTINÊNCIA DA ABORDAGEM DPP PARA SEU ESTUDO}

A compreensão da política urbana brasileira e da pertinência da abordagem DPP para seu estudo depende de uma contextualização histórica mínima do desenvolvimento da questão urbana no país. O tratamento legislativo da questão urbana passou, nas últimas décadas, por um notável incremento. Longe de ser fruto do acaso ou de uma ação preventiva do Poder Público, o aprofundamento da pauta ocorreu em um contexto peculiar. Intensificada principalmente a partir da segunda metade do século XX, a urbanização brasileira tem como marcas amplamente reconhecidas a aplicação discriminatória da lei (Maricato, 2000; Rolnik, 2001) e a ausência de regulação efetiva dos particulares pelo Estado, resultando em um processo constante de apropriação dos ganhos econômicos da urbanização por uma minoria.

Essa apropriação desigual se deu à custa da produção de cidades que têm em comum dois traços essenciais: a segregação espacial e a exclusão social. Traços esses que compõem o pano de fundo das mazelas urbanas que atingem a maioria das populações urbanas: degradação ambiental, violência urbana, déficit habitacional, precariedade de serviços públicos, congestionamento, baixa mobilidade e a combinação de todos esses fatores de miséria social com a própria miséria urbana, tal qual descrita por Henri Lefebvre (2001).

A escala do complexo problema social em questão pode ser ilustrada pelo fato de que cerca de $85 \%$ da população brasileira vivem hoje em cidades, sendo que apenas as regiões metropolitanas abrigam mais de 100 milhões de pessoas (IBGE, 2010). Nesse quadro, para além de terem se tornado o palco principal das reivindicações sociais por direitos, as cidades se tornaram também objeto das tensões sociais. Como destaca David Harvey (2014, p. 230-231), a luta de classes no 
interior das cidades, atinente, em princípio, à exploração oriunda da relação capital-trabalho, funde-se à luta pelos direitos de cidadania, que dizem respeito a formas secundárias de exploração, cujos efeitos se desdobram onde as pessoas vivem, e não mais onde trabalham.

Especialmente a partir da década de 1970, o agravamento dos problemas urbanos no Brasil e a crescente organização dos movimentos sociais impulsionada, adiante, pelo processo de redemocratização - direcionaram a tensão política, entre outras vias, para a intensificação das demandas por direitos nas cidades. É nesse contexto de conflitos políticos que se dá a evolução dos marcos jurídico-institucionais do direito urbanístico.

A iniciar pela inédita constitucionalização da política urbana a partir da CF/1988, indissociável da Emenda Constitucional de Iniciativa Popular de Reforma Urbana, elaborada por seis entidades de categorias profissionais e movimentos populares e assinada por mais de 130 mil eleitores (MARICATO, 2000, p. 143). O Estatuto da Cidade (Lei 10.257/2001), por sua vez, tem origem em projeto de lei que tramitou intensamente por mais de uma década no Congresso Nacional, sendo resultado de muita negociação entre os agentes envolvidos, incluídos os movimentos sociais. Da mesma forma, conforme Maricato (2011, p. 24), a criação do Ministério das Cidades, em 2003, se deu por via cuja pavimentação foi consolidada "por muitos e sucessivos passos dados por um número cada vez maior de lideranças sociais, profissionais e técnicas de diversas origens". Isso para citar três dos muitos exemplos, nacionais e locais, nesse sentido.

Portanto, a incorporação, ao direito positivo, das resultantes desse embate social e do acúmulo das formulações dos movimentos urbanos, da produção acadêmica pertinente e dos debates internacionais sobre a organização urbana positivados especialmente na forma de direito sociais - foi o principal fator a conformar uma legislação de viés transformador. Contudo, grosso modo, a legislação que deveria impulsionar a transformação, servindo de meio à consecução dos objetivos nela estampados, acabou, em muitos casos, tomada por fim em si, reforçando a retórica que encobre a tradicional aplicação discriminatória da legislação urbanística no Brasil. Apesar de avanços concretos importantes em diversas searas da política urbana ${ }^{3}$, há, ainda, sinais insuficientes de que estejamos à caminho da superação do grande descompasso entre as prescrições normativas e o padrão de políticas públicas implementadas nas principais cidades brasileiras. A despeito do apontamento de mudanças pela legislação, tais políticas, não raro, vêm reforçando parte dos elementos responsáveis pela atual configuração do território

\footnotetext{
${ }^{3}$ Como exemplos, podem ser mencionados, além de outros: o aumento da produção de moradias de interesse social - sobretudo, por meio do Programa Minha Casa Minha Vida; a melhoria das condições do transporte público urbano em muitas capitais, com a construção de metrôs, corretores de ônibus, VLTs (veículos leves sobre trilhos), faixas exclusivas de ônibus, ciclovias etc.; o incremento da oferta de serviços de saneamento básico, embora ainda em níveis muito inferiores ao necessário.
} 
urbano, socialmente excludente e espacialmente segregado (MARICATO, 2000; 2011; ROLNIK, 2012; FERNANDES, 2006).

Naturalmente, entraves políticos e jurídicos, imbricados entre si, estão no cerne da explicação sobre esse descompasso. Um primeiro exemplo disso diz respeito ao modelo de federalismo adotado pela CF/1988, composto por três níveis de governo (União, Estados e Municípios, seguindo a tradição municipalista brasileira). A CF/1988 distribuiu entre tais níveis, de modo complexo e com nível de detalhamento variado, competências legislativas, tributárias e materiais. Conforme Arretche (2004), concretamente, essa forma de distribuição combinou elementos centralizadores e descentralizadores, o que, muitas vezes, gera algum nível de fragmentação ao modelo. Com isso, mesmo quando o critério de distribuição adotado foi expressamente tratado pela Constituição (o que nem sempre ocorre), demanda-se um notável esforço de coordenação e cooperação entre os entes federativos (Silva, 2010), que não pode ser feito senão a partir da intensa mobilização de soluções de natureza jurídica.

Uma breve e não exaustiva descrição da repartição federativa de competências em torno da questão urbana e dos transportes urbanos indica claramente essa necessidade de cooperação entre os entes.

O artigo 21 da CF/1988 conferiu à União competência para instituir os princípios e as diretrizes do desenvolvimento urbano (inciso XX) - inclusive habitação, saneamento básico e transportes urbanos - e as diretrizes do sistema nacional de viação (inciso XXI), que também é integrado pelo viário urbano. $\mathrm{O}$ artigo 22, a seu turno, estabeleceu como competência privativa da União legislar sobre direito civil (inciso I), desapropriação (inciso II) e sobre trânsito e transporte (inciso XI). Já o artigo 24 dispôs como competência concorrente de União, Estados e Municípios legislar sobre direito urbanístico (inciso I).

Em contrapartida, a execução da política de desenvolvimento urbano, cujos princípios e diretrizes são estabelecidos pela União, foi deixada a cargo dos Municípios, conforme disposto no artigo 182, que inaugura o capítulo constitucional sobre política urbana. O artigo 30 da CF/1988 atribuiu aos Municípios competência para legislar sobre assuntos de interesse local (inciso I) e para organizar e prestar serviços públicos de interesse local, dentre os quais o transporte urbano, caracterizado como essencial pelo constituinte (inciso V). Se consideradas competências de outras matérias caras à política urbana, como meioambiente, saneamento básico, habitação e segurança pública, bem como sua desarmonia com a garantia de fontes orçamentárias, a complexidade do modelo se torna ainda mais patente.

Nota-se, então, que a distribuição das competências atinentes à formulação e execução das diversas políticas públicas que compõem a política urbana depende, decisivamente, de uma interação qualificada e intensa entre os entes federativos. A própria natureza multidisciplinar da questão urbana, cujo endereçamento 
pressupõe a convergência de programas de ação governamental em diferentes frentes, amplia o desafio dessa interação, na medida em que o necessário diálogo intersetorial dentro de cada esfera de governo facilmente transborda para o diálogo institucional federativo.

Evidente, nesse sentido, que as normas gerais estabelecidas pela União constituem apenas um passo inicial à formulação da política urbana, a partir das quais caberão aos Municípios a formulação e aplicação de legislações próprias, dando consequência aos princípios, objetivos e instrumentos da política urbana no arranjo institucional local e, com isso, criando as condições para que promovam e executem essa política de modo a torná-la eficaz no plano material. A racionalidade por trás do arranjo é justamente deixar a cargo do gestor "da ponta" a adaptação dos objetivos gerais à realidade local específica, considerando aspectos geográficos, ambientais, culturais, sociais e assim por diante.

Para além da complexidade que permeia o aparato institucional envolvido, há uma particularidade digna de nota da política urbana em relação às políticas públicas em geral. É natural que o processo de elaboração e implementação de políticas públicas seja permeado por conflitos distributivos, sendo a manifestação mais óbvia e frequente a disputa em torno do orçamento público, sempre escasso frente às diversas demandas da sociedade. Ocorre que, no caso da política urbana, esse conflito distributivo é significativamente realçado por dois fatores.

Em primeiro lugar, a escassez de recursos no âmbito da política urbana extrapola o âmbito orçamentário, referindo-se, antes de tudo, à distribuição da própria terra urbana e da infraestrutura nela instalada entre os diferentes usos e atores sociais. Quanto mais intenso e consolidado o processo de urbanização em um quadro de desigualdades sociais, maior tende a ser a escassez de terra. Cabe lembrar, conforme anota Maricato (2011, p. 186), que "a questão [ou o "nó"] da terra continua a se situar no centro do conflito social [brasileiro], mas de forma renovada", alimentando a profunda desigualdade e a tradicional relação entre propriedade, poder político e poder econômico.

Assim, a política urbana, em suas diversas manifestações, lida diretamente com o conflito social histórico em torno do acesso à terra, o que traz diversas implicações políticas e jurídicas à sua formulação e execução. Embora as desigualdades sociais estejam no cerne do conflito, é preciso reconhecer que há uma multiplicidade de interesses afetados pela política de uso e ocupação do solo - núcleo da política urbana -, reflexo dos diversos usos a que a terra urbana pode servir. Além disso, há que se notar que para cada instrumento oferecido pelo direito para solucionar os problemas urbanos e transformar sua realidade, há outros tantos entraves oferecidos pelo próprio direito, constantemente mobilizados para manter e conservar o status quo. As dificuldades impostas pelo Poder Judiciário para a realização de desapropriações administrativas - fundamentais à função do Poder Público municipal de ordenação do território - constituem um dos grandes exemplos nesse sentido. 
Em segundo lugar, deve-se ter em conta a realidade sobre a qual a política urbana incide. Conforme já afirmado, os territórios da grande maioria das cidades brasileiras são fortemente marcados pela exclusão social e pela segregação espacial, fatores que estão na matriz de praticamente todos os problemas urbanos. Mais do que isso, esses traços característicos se devem ao fato de a produção do espaço urbano estar inserida em uma lógica de acumulação capitalista, a partir da qual os incrementos de renda derivados do processo de urbanização são apropriados por uma minoria. Isso se dá em um cenário de tensão entre concentração e expansão geográfica, que traz diversas externalidades à vida urbana. Dentre outras implicações, tal quadro indica que, para além do caráter distributivo inerente à própria natureza da questão urbana - que lida com a gestão de um bem escasso, a situação fática colocada impõe um desafio necessariamente redistributivo, exigindo que se rompa com uma lógica de produção espacial que aprofunda as desigualdades sociais, visando, enfim, à garantia o direito à cidade.

Em resumo do exposto até aqui, é possível tecer uma síntese do que se pretendeu mostrar, explicitando as vantagens analíticas oferecidas pela utilização da abordagem DPP ao estudo da política urbana.

Em primeiro lugar, em linha com a formulação de Ewald (1988), pode-se dizer que o direito à cidade, cuja efetivação é a finalidade última da política urbana, é um direito social por excelência, não sendo possível se cogitar de sua concretização senão a partir de uma perspectiva coletiva. Do ponto de vista material, esse é o campo em relação ao qual a abordagem DPP se mostra mais promissora, permitindo articular, em uma mesma pesquisa, a base normativa do direito, a estrutura organizativa responsável por garanti-lo, os mecanismos de coordenação das diversas instâncias do aparato institucional correspondente e, ainda, as questões jurídicas controvertidas atreladas à efetivação do direito em questão. ${ }^{4}$

No caso específico da política urbana, como se viu, a estrutura organizativa corresponde a uma divisão de competências entre os diferentes entes federativos, agravada pelo fato de sua natureza demandar a mobilização e convergência de diversas áreas do governo, sendo a intersetorialidade um pressuposto inafastável de sua formulação e execução. Trata-se, assim, de uma política cuja responsabilidade é atribuída a um complexo arranjo institucional, demandando uma interação qualificada entre os agentes envolvidos, de modo que os traços jurídicos externos antes mencionados são aqui particularmente relevantes para entender a direção das políticas públicas em questão.

O caráter multidisciplinar da política urbana, que exige a combinação de conhecimentos de diversos setores (infraestrutura, transporte, saúde, saneamento, cultura etc.) e de diversas expertises (engenharia, arquitetura, gestão, economia, direito etc.), pode ser apontado como outro ponto de convergência em relação à

${ }^{4}$ Sobre isso, ver o artigo de Bucci publicado neste dossiê. 
abordagem DP. Como visto na seção anterior, tal abordagem pressupõe a articulação de diferentes áreas do conhecimento e tem aptidão para buscar os pontos de conexão entre elas, identificando os impactos de seus encontros (e desencontros) na elaboração e implementação das políticas públicas.

O mesmo raciocínio se aplica internamente à própria área do direito. Do ponto de vista jurídico, a compreensão da política urbana depende de um olhar amplo e multifocal, posto que as condições para sua execução dependem da interpretação articulada de normas de Direito Constitucional, Direito Administrativo, Direito Financeiro, Direito Ambiental, Direito Urbanístico e Direito Civil, para ficar nos principais. Como mencionado, não raro, os entraves à efetivação da política urbana são opostos pelo próprio Direito. Ao intensificar a exploração das conexões com campos estabelecidos na ciência do Direito, a abordagem DPP, ela mesma, tende a ganhar maior relevância. ${ }^{5}$

Por fim, a política urbana tem sua organização dificultada por um conflito distributivo particularmente realçado - atinente ao chamado "nó da terra". Tal conflito diz respeito principalmente ao quadro de desigualdades sociais posto no meio urbano, mas também se nota em sua órbita uma multiplicidade de interesses contraditórios que se colocam a partir de outros recortes. O endereçamento desses conflitos a partir da elaboração da política de uso e ocupação do solo, amplamente compreendida, é desafiada por uma realidade complexa e, especialmente, pela inserção do processo de produção do espaço urbano em uma lógica excludente de acumulação. Vale notar que, à luz dos dados demográficos, a questão urbana no Brasil é, em grande medida, um tema metropolitano, já que mais da metade da população brasileira vive hoje nas cidades que integram regiões metropolitanas.

Diante disso, a utilização de uma abordagem que, para o estudo das políticas públicas, pressupõe a apreensão do direito "em movimento", a consideração da escala dos problemas, a aplicação de um olhar prospectivo e o protagonismo do Poder Executivo, facilita enormemente a análise de programas de ação governamental integrantes da política urbana. Destaca-se, ainda, a especificidade relativa à atenção às normas regulamentares infralegais, de notável importância ao direito urbanístico, sobretudo pela capacidade de influenciar, na ponta, a execução das políticas públicas.

A seguir, na última seção deste artigo, buscar-se-á ilustrar, concretamente, os pontos de convergência aqui descritos, trazendo alguns aspectos da experiência da pesquisa de mestrado do autor sobre a função social das vias urbanas (Haddad, 2019) para robustecer a defesa da pertinência da abordagem DPP ao estudo jurídico da política urbana no Brasil.

\section{A CONTRIBUIÇÃO DA ABORDAGEM DPP AO ESTUDO DAS VIAS}

\footnotetext{
${ }^{5}$ Sobre isso, ver o artigo de Bucci publicado neste dossiê.
} 


\section{URBANAS E SUA FUNÇÃO SOCIAL}

Para tratar das contribuições da abordagem DPP à dissertação de mestrado que desenvolvi, ilustrando concretamente a pertinência do método ao estudo da política urbana (defendida em abstrato na seção anterior), será preciso descrever, sinteticamente, o trabalho em si, passando pela delimitação do tema, seus objetivos, a estrutura adotada e alguns dos achados de pesquisa. Em meio a essa descrição, serão feitas considerações sobre a própria contribuição da abordagem e as influências que produziu sobre as escolhas feitas ao longo da elaboração da dissertação.

De início, vale situar o objeto vias urbanas em relação à política urbana. A nosso ver, as políticas públicas atinentes às vias urbanas dizem respeito, fundamentalmente, à definição, regulação e gestão de seus diferentes usos. Dessa feita, tal política, de caráter multifacetado, situa-se na fronteira entre, de um lado, a política urbana em geral, com enfoque nas atividades de planejamento urbano (amplamente compreendida) e de regramento do uso e ocupação do solo, e, de outro, a política de mobilidade urbana, parte integrante da primeira e que se concentra nas atividades de organização dos transportes urbanos - atinente à construção da infraestrutura de transporte - e de organização da circulação relacionada ao regramento do uso dessa infraestrutura.

Trata-se, em essência, da árdua e conflituosa tarefa de distribuir um espaço que, embora corresponda à parte expressiva da totalidade da terra urbana, é notoriamente insuficiente à atenção de todas as demandas que lhe têm como objeto, que extrapolam largamente a função de circulação e o direito ao transporte ${ }^{6}$. Ou seja, se o conflito distributivo é realçado quando se trata da política urbana em

\footnotetext{
${ }^{6}$ Conforme defendi na dissertação: “[...] as vias urbanas estão muito longe de se limitarem a servir como canal de locomoção. Para além do uso pelos diversos meios de transporte de pessoas e mercadorias que comporta, há uma série de outras funções ligadas ao direito à cidade que se relacionam diretamente à fruição da rua. Manifestações políticas, como passeatas e protestos de rua; intervenções culturais, a exemplo da expressão dos artistas de rua, do carnaval, "pancadões", festividades de São João e demais festas de rua; atividades comerciais, entre as quais aquelas promovidas por feiras livres, bancas de jornal, vendedores ambulantes, permissionários ("camelôs") e a chamada comida de rua; eventos esportivos, como maratonas, competições de ciclismo e mesmo a prática amadora de exercícios físicos; o gozo de espaços de lazer e convivência, como bancos, praças e os chamados 'parklets'; a fruição de um meio ambiente saudável, que depende, entre outras coisas, da distribuição de áreas verdes por todo o território urbano; a instalação da infraestrutura das redes áreas e subterrâneas de iluminação, saneamento e comunicação; a função de canal de passagem de luz e ar entre as edificações; a preservação histórica da memória, que inclui a presença de monumentos e placas pela cidade e a denominação dos próprios logradouros; o emergente uso de conexão pública de internet nos espaços comuns. Todas essas dimensões vitais da dinâmica das cidades, que extrapolam em grande escala a questão da mobilidade urbana, têm como elemento central o acesso e o uso das vias urbanas, suporte de todo o tipo de 'troca' no meio urbano' (Haddad, 2019, p. 111).
} 
geral, tem-se nas políticas atinentes às vias urbanas uma manifestação singular desse conflito: cada palmo do espaço público urbano de circulação é diretamente disputado entre os diferentes usos e atores sociais, impondo um desafio enorme à gestão desse bem público de uso comum.

A escolha da categoria função social para tratar dessa atividade de gestão foi decisão fortemente inspirada na abordagem DPP, sendo essa uma das primeiras contribuições a ser apontada. Por seu caráter mutante e permeável às disputas em torno do alcance de seu significado ${ }^{7}$, trata-se de princípio constitucional capaz de comunicar as tensões existentes entre o político e o jurídico, mostrando-se transversal a ambos os planos e, justamente por isso, servindo a evidenciar sua relação de interdependência. Sua escolha se deveu, então, ao objetivo de buscar estabelecer as conexões entre os conflitos políticos e o complexo regime jurídico que, de modo imbricado, incidem sobre as vias urbanas e a atividade de sua gestão.

A partir dessa escolha, buscou-se responder à seguinte indagação: qual o conteúdo do princípio da função social da propriedade aplicado às vias urbanas e quais os parâmetros jurídicos de aferição do seu cumprimento? Pontua-se que uma das inquietações que a motivaram diz respeito a certo contraste entre as formulações que dão sentido à aplicação do mesmo princípio à propriedade privada - seja rural ou urbana - e a aparente incompreensão generalizada sobre os critérios a partir dos quais se verifica o cumprimento da função social da propriedade por um bem público ${ }^{8}$ de importância vital à vida comunitária no Brasil contemporâneo: a "rua".

A intenção desse questionamento foi a de, partindo da perspectiva do Poder Público local, contribuir com a complexa gestão das vias urbanas por meio da produção de políticas públicas capazes de garantir que estas atendam sua função social, "mostrando o que está em jogo em suas decisões políticas de alocação e regulação dos usos das vias, quais são seus deveres em relação a essa tarefa e quais os instrumentos à sua disposição para a consecução dos objetivos juridicamente determinados" (HADDAD, 2019, p. 21). O enfoque, portanto, escapa à tradicional abordagem em torno de como a organização das cidades afeta as vias urbanas e seu funcionamento, priorizando a análise do impacto das decisões sobre os usos das vias sobre a organização urbana, sem prejuízo de anotar as relações de influência mútua.

A estratégia para empreender essa proposta, refletida expressamente na estrutura do trabalho, é outro ponto tributário da abordagem DP. A dissertação foi

\footnotetext{
${ }^{7}$ Em um dos tópicos do capítulo 4 da dissertação, buscou-se mostrar a influência da emergência do direito à cidade sobre a ressignificação do princípio da função social da propriedade, que passou a ser incorporado à pauta de reivindicações dos movimentos sociais urbanos, depois de já ter sido utilizado como pretexto para a realização de reformas urbanas excludentes (Haddad, 2019, p. 237242).

${ }^{8}$ Outro tópico do capítulo 4 prestou-se ao posicionamento sobre a aplicabilidade do princípio da função social aos bens públicos, em linha com o que defende a doutrina majoritária brasileira (Haddad, 2019, p. 228-237)
} 
dividida em quatro capítulos: (1) problematização do objeto vias urbanas, a partir de considerações sobre as decisões que marcaram a produção e gestão das vias urbanas, contextualizadas à luz do quadro mais amplo de produção do espaço urbano; (2) delimitação das vias urbanas enquanto objeto de estudo jurídico, a partir de formulações sobre seu conceito, classificação e formação jurídica; (3) sistematização do regime jurídico que incide sobre as vias urbanas no ordenamento jurídico brasileiro, encerrada com uma proposta de tipologia sobre as decisões políticas atinentes ao regramento do uso das vias urbanas; e (4) apresentação da aplicação do princípio da função social da propriedade às vias urbanas, utilizandose como campo de aplicação de questões contemporâneas complexas, como o destino de uma via elevada herdada do período autoritário (o "Minhocão") e a regulação municipal dos aplicativos de transporte individual privado motorizado.

Assim, em linha com a abordagem DPP, nota-se, de pronto, uma tentativa de cercar o problema proposto sob várias óticas, combinando a multidisciplinaridade com o estabelecimento de conexões entre as próprias áreas da ciência jurídica. Esses elementos são facilmente visualizáveis a partir do tipo de referência bibliográfica que apoiou o desenvolvimento de cada parte da dissertação:

- O capítulo 1 , de viés mais crítico, teve enfoque em elementos não jurídicos que contextualizassem o objeto do trabalho à luz da realidade fática, sendo apoiada, principalmente, pela produção pertinente de economia urbana, geografia crítica, urbanismo, história e ciências sociais, destacando-se os aspectos referentes à regulação jurídica;

- O capítulo 2, centrado no conceito jurídico de vias urbanas e no processo jurídico de formação das vias urbanas, se debruçou sobre a doutrina nacional e estrangeira de direito urbanístico, recorrendo também à legislação federal e, em alguns pontos, à municipal;

- O capítulo 3 se concentrou na literatura nacional de direito administrativo, especialmente aquela que trata dos bens públicos e sua função social, analisando também a legislação pertinente a esse recorte;

- Por fim, o último capítulo partiu das sínteses extraídas dos demais capítulos e, em alguns pontos, de obras de filosofia do direito para tratar da noção de função social da propriedade e sua aplicação às vias urbanas.

Algumas escolhas de abordagem feitas para o endereçamento da proposta de cada capítulo também são ilustrativas da contribuição da abordagem DPP e de suas recomendações à análise de programas de ação governamental.

No capítulo 1, destaca-se o esforço para compreender não apenas o atual estado de coisas e os processos políticos que conduziram a tal, como também para identificar o tipo de política pública que esteve por trás da atual conformação das vias urbanas - seja do ponto de vista de sua infraestrutura, seja da perspectiva dos 
usos que lhe são atribuídos. Nesse sentido, anotou-se que a relação entre organização dos transportes urbanos e organização da circulação, sob a ótica da conformação das vias urbanas, constitui um provável exemplo da ideia de intermitência de políticas descrita como mixed scanning (ETZIONI, 1967). Melhor explicando, buscou-se demonstrar que a adoção da política rodoviarista manifestação da disputa pelo acesso à terra e à infraestrutura nela fixada constituiu decisão estruturante, que orientou por período longo de tempo as políticas subsequentes, que acabaram por perpetuar sua lógica, sem maiores questionamentos e discussões, de modo incremental (LINDBLOM, 1976).

Nesse sentido, tentou-se desnudar o cerne do rodoviarismo, tirando o foco da questão da substituição entre modais de transporte e passando-o ao que se entende como ponto fulcral dessa política: a decisão de franquear a infraestrutura pública de transporte ao uso irrestrito por uma parcela minoritária da população - cujo recorte é indissociável a uma divisão de classe - implica criar condições para que uma desigualdade de origem se desdobre em diversas outras formas de iniquidade, servindo como fator intergeracional de reprodução de classe. A partir do modelo proposto por Lowi (1995), inferiu-se que se trata de uma política de caráter distributivo, já que implica a distribuição de um bem público coletivo rival a partir de um processo descentralizado, fragmentado e local, sem um critério positivado ou expresso (LOWI, 1995, p, 183).

Ainda em referência à formulação abstrata de Lowi, apontou-se concretamente que essa política foi adotada como única possível, sem que se reconhecesse a possibilidade de adotar outros padrões. Assim, em prejuízo da formulação de políticas suficientemente abrangentes para beneficiar um grande número de pessoas (políticas constitutivas) ou de claramente se direcionar os benefícios e ônus da política a partir de uma moralidade pública sobre ações até então tidas como privadas (políticas redistributivas), optou-se, veladamente, por uma política que agrava as desigualdades e que "claramente se aproxima da completa privatização do público" (LOWI, 1995, p. 198).

Em relação aos capítulos 2 e 3, vale mencionar o esforço de sistematização dos institutos e normas jurídicas atinentes às políticas públicas que incidem sobre as vias urbanas, permitindo uma descrição analítica do arranjo jurídico-institucional envolvido, bem como a formulação de considerações críticas sobre suas incongruências em relação às necessidades sociais colocadas. Assim, buscou-se aplicar, na prática, a ideia de apreensão do direito "em ação", partindo de uma visão prospectiva sobre a possibilidade de contribuição do direito ao aperfeiçoamento das políticas públicas. Nesse sentido, em que pese o conteúdo predominantemente jurídico de ambos os capítulos, os conflitos políticos por trás das normas foram destacados sempre que possível.

Especialmente no capítulo 2, sublinha-se a problematização dos instrumentos urbanísticos e do próprio conceito jurídico de via urbana - aproveitando a contextualização do objeto procedida no capítulo 1 -, bem como a descrição 
articulada do processo jurídico de formação das vias urbanas com o processo jurídico envolvido no processo mais amplo de urbanificação (SILVA, 2012).

Já no capítulo 3, há dois pontos dignos de nota derivados da sistematização das normas legais e infralegais atinentes à gestão das vias urbanas. Primeiro, nesse capítulo, essa sistematização teve enfoque principal em dissecar a Política Nacional de Mobilidade Urbana, oferecendo uma visão organizada de suas principais disposições. Em segundo lugar, essa sistematização permitiu, ao final do capítulo, apresentar uma proposta original de tipologia das decisões políticas relativas aos usos das vias urbanas e seu regramento. Nesse ponto, fica evidente, em consonância com a abordagem DPP, a adoção do ponto de vista do Poder Executivo, bem como a atenção às normas regulamentares, cuja análise muito contribuiu a esse esforço de sistematização.

Enfim, em relação às escolhas de abordagem do objeto do capítulo 4, pode-se citar, como principal escolha feita em vista da abordagem DPP, a utilização de dois casos concretos como campo de aplicação dos preceitos teóricos até então trabalhados de modo mais abstrato. Com isso, buscou-se não apenas colocar à prova a estrutura analítica sustentada pela dissertação, como também concatenar, a partir de comparações temporais e geográficas que situassem as políticas públicas em questão, os elementos que compõem o processo de maturação de entendimentos sobre a adequada gestão das vias urbanas. No mesmo capítulo, o destaque à categoria da função social e o aprofundamento de aspectos relacionados à sua origem e à disputa em torno de seu conteúdo contribuíram, ainda, para jogar luz sobre os atores envolvidos e os interesses que representam, colocando lado a lado os fatores políticos e jurídicos atinentes à gestão das vias urbanas.

Em um último esforço de síntese, novamente realçando a visão prospectiva e em vistas da possibilidade de aprimoramento das políticas públicas, a dissertação buscou resumir o raciocínio empreendido ao longo do texto a partir de três formulações:

\begin{abstract}
"1- As vias urbanas se confundem com a cidade e as decisões sobre seus usos influenciam de modo determinante a organização urbana, o que impõe a necessidade de reflexão ampla e profunda sobre a metodologia a ser adotada em sua gestão;

2- Essa metodologia deve ter como necessário ponto de partida a compreensão sobre as dramáticas consequências do modelo rodoviarista e sua contribuição para a conformação de um território desigual e segregado ${ }^{[9]}$, que, primeiro, aniquilou os
\end{abstract}

\footnotetext{
9 Sobre isso, vale citar a contundente explicação de Milton Santos: "As cidades, e sobretudo as grandes, ocupam, de modo geral, vastas superfícies, entremeadas por vazios. Nessas cidades espraiadas, características de uma urbanização corporativa, há interdependência do que podemos chamar de categorias espaciais relevantes desta época: tamanho urbano, modelo rodoviário, carência de infra-estruturas, especulação fundiária e imobiliária, problemas de transporte,
} 
diversos usos secundários das vias urbanas para, depois, mostrarse incapaz de garantir inclusive as mínimas condições de um modelo de mobilidade seguro, eficiente e acessível, trazendo diversas perdas de bem-estar social, bem como dos potenciais ganhos da economia de aglomeração;

3- A partir desse diagnóstico e do preenchimento do princípio da função social da propriedade por meio de diversas formulações sobre direito à cidade, é possível empreender, de modo simples e objetivo, a interpretação do atual regime jurídico das vias urbanas e a mobilização de seus instrumentos de modo a efetivamente iniciar um processo de reversão do modelo vigente e de abertura das cidades para as pessoas, aproximando-se dos objetivos constitucionais de justiça social, desenvolvimento humano e preservação do meio-ambiente. A despeito do gigantesco conflito distributivo inerente à questão colocada, outro modelo de cidade é possível e a adequada gestão dos usos de suas vias é parte decisiva da necessária transformação do meio urbano em favor dos interesses coletivos das populações que o habitam." (HADDAD, 2019, p. 304-305).

\section{CONSIDERAÇÕES FINAIS}

Dialogando com uma agenda de balanço da abordagem DPP e de organização do conhecimento coletivamente acumulado em torno de sua aplicação, o presente artigo buscou evidenciar as possibilidades de contribuição da referida abordagem ao estudo da política urbana no Brasil. Para tanto, foi feita uma reflexão em três partes.

extroversão e periferização da população, gerando, graças às dimensões da pobreza e seu componente geográfico, um modelo específico de centro-periferia. Cada uma dessas realidades sustenta e alimenta as demais e o crescimento urbano é, também, o crescimento sistêmico dessas características. As cidades são grandes porque há especulação e vice-versa; há especulação porque há vazios e vice-versa; porque há vazios as cidades são grandes. O modelo rodoviário urbano é fator de crescimento disperso e do espraiamento da cidade. Havendo especulação, há criação mercantil da escassez e o problema do acesso à terra e à habitação se acentua. Mas o déficit de residências também leva à especulação e os dois juntos conduzem à periferização da população mais pobre e, de novo, ao aumento do tamanho urbano. As carências em serviços alimentam a especulação, pela valorização diferencial das diversas frações do território urbano. A organização dos transportes obedece a essa lógica e torna ainda mais pobres os que devem viver longe dos centros, não apenas porque devem pagar caro seus deslocamentos como porque os serviços e bens são mais dispendiosos nas periferias. $\mathrm{E}$ isso fortalece os centros em detrimento das periferias, num verdadeiro círculo vicioso." (1993, p. 96-97). 
Como ponto de partida, foram apresentadas algumas das principais características da abordagem DPP, em especial, suas premissas, estratégias e o "norte" que recomenda em sua aplicação.

Entre as premissas, destaca-se a compreensão de que: as políticas públicas são conformadas por elementos jurídicos que desempenham múltiplas funções em seu processo de produção e execução; sendo que as ricas possibilidades de apreensão de seu conteúdo e forma a partir dos traços jurídicos exteriores de sua estrutura colocam o direito, ao lado de outras áreas, como ótica privilegiada para observálas; de modo a permitir, inclusive, que se vislumbre o seu aprimoramento em termos de eficiência, legitimidade e eficácia a partir de soluções e formulações pensadas a partir do direito.

Já entre as estratégias, foram apresentadas em maior detalhe a adoção da perspectiva do Poder Executivo, a consideração da escala dos problemas a que as políticas públicas se dirigem, a direção de uma visão prospectiva sobre as políticas públicas e seu arranjo institucional, a utilização de recursos multidisciplinares para seu estudo e a atenção reforçada ao papel das normas regulamentares na fase de implementação das políticas públicas.

Finalmente, pontuou-se como norte principal da abordagem a ideia de se colocar lado a lado os seus aspectos jurídicos e políticos, examinando as influências recíprocas entre ambos no processo de elaboração e execução das políticas públicas. Desse modo, a compreensão estruturada e sistemática das tensões existentes entre o político e o jurídico e a capacidade de comunicá-las estão entre os objetivos da abordagem, oferecendo condições favoráveis para a identificação, a discussão e o aperfeiçoamento das relações estabelecidas entre as políticas públicas e seu arcabouço jurídico.

À luz dessas considerações sobre a abordagem, tratou-se, em seguida, das características da política urbana que tornam promissora a utilização da abordagem DPP ao seu estudo. Em apertada síntese, os principais pontos de convergência se devem ao fato de a política urbana: (i) ter por finalidade a garantia de direitos sociais, em especial do direito à cidade, caracterizados por sua fruição coletiva; (ii) ser caracterizada por uma transversalidade em relação às áreas de governo mobilizadas, reforçando a necessidade de uma abordagem multidisciplinar; (iii) depender da operação de um arranjo institucional complexo, que exige uma interação federativa qualificada, agravada pela necessidade de combinar o diálogo federativo à harmonia entre as diferentes áreas envolvidas em cada esfera de governo; (iv) pressupor uma interpretação sistemática de normas de Direito Constitucional, Administrativo, Ambiental, Urbanístico, Financeiro e Civil, mostrando-se terreno fértil para se explorar as conexões e os desencontros entre as diversas áreas da ciência jurídica, tarefa para a qual a abordagem DPP também está vocacionada; (v) ter sua consecução dificultada por uma série de entraves jurídicos, imbricados a conflitos políticos de diversas naturezas; (vi) materializar, na sua 
própria essência, o conflito distributivo de modo realçado, envolvendo a mediação entre uma multiplicidade de interesses contrapostos; e, por fim, (vii) ilustrar, de modo enfático, um profundo descompasso entre prescrições normativas (cidade legal) e realidade fática (cidade real), em relação a que a pesquisa jurídica não deve ficar imune.

Por fim, para exemplificar concretamente esses pontos de contato, foram apresentados aspectos pertinentes relacionados à aplicação da abordagem DPP ao estudo jurídico das vias urbanas e sua função social, pesquisa de dissertação do autor (HADDAD, 2019).

\section{REFERÊNCIAS}

ARRETCHE, Marta. Federalismo e políticas sociais no Brasil: problemas de coordenação e autonomia. São Paulo em Perspectiva, v.18, n. 2, 2004, p.17-26.

BUCCI, Maria Paula Dallari. Fundamentos para uma teoria jurídica das políticas públicas. São Paulo : Saraiva, 2013.

BUCCI, Maria Paula Dallari. Contribuição para a redução da judicialização da saúde. Uma estratégia jurídico-institucional baseada na abordagem Direito e Políticas Públicas. In: BUCCI, Maria Paula Dallari; DUARTE, Clarice Seixas (coords.). Judicialização da saúde: a visão do poder executivo. São Paulo: Saraiva, 2017.

BUCCI, Maria Paula Dallari. Método e aplicações da abordagem Direito e Políticas Públicas. Revista Estudos Institucionais, v. 5, n. 3, 2019.

BUCCI, Maria Paula Dallari; COUTINHO, Diogo R. Arranjos jurídicoinstitucionais da política de inovação tecnológica: uma análise baseada na abordagem de direito e políticas públicas. In: COUTINHO, Diogo R; FOSS, Maria Carolina; MOUALLEN, Pedro Salomon B. (orgs.). Inovação no Brasil: avanços e desafios jurídicos e institucionais. São Paulo: Blucher, 2017.

ETZIONI, Amitai. Mixed-Scanning: a third approach to decision-making. Public Administration Review, v. 27, n. 5, 1967, p. 385-392.

EWALD, François. A concept of social Law. In: TEUBNER, Gunther (ed.).

Dilemmas of Law in the Welfare State. New York: Walter de Gruyter, 1988. 
FERNANDES, Edésio. A nova ordem jurídico-urbanística no Brasil. In: ALFONSIN, Betânia; FERNANDES, Edésio (orgs.). Direito urbanístico: estudos brasileiros e internacionais. Belo Horizonte: Del Rey, 2006.

HADDAD, Frederico. Função Social das Vias Urbanas: Uma análise à luz da teoria jurídica das políticas públicas. Dissertação (Mestrado em Direito) Faculdade de Direito, Universidade de São Paulo, São Paulo, 2019.

HARVEY, David. Cidades Rebeldes: do direito à cidade à Revolução urbana. São Paulo : Martins Fontes, 2014.

LEFEBVRE, Henri. O direito à cidade. São Paulo: Centauro, 2001.

LINDBLOM, Charles E. Muddling through 2: a ubiqüidade da decisão incremental (1976). Trad. Francisco G. Heidemann. In: HEIDEMANN, Francisco G.; SALM, José Francisco. Políticas públicas e desenvolvimento: bases epistemológicas e modelos de análise. Brasília: UnB-Esag/Udesc, 2006.

LOWI, Theodore. Public Policy Theories, Models, and Concepts. New Jersey: Prentice-Hall, 1995.

MARICATO, Ermínia. O impasse da política urbana no Brasil. São Paulo: Editora Vozes, 2011.

MARICATO, Ermínia. As idéias fora do lugar e o lugar fora das idéias. In: ARANTES, Otília; VAINER, Carlos; MARICATO, Ermínia (orgs.). A cidade do pensamento único: desmanchando consensos. Petrópolis: Vozes, 2000.

ROLNIK, Raquel. A cidade e a lei: legislação, política urbana e territórios na cidade de São Paulo. São Paulo: Studio Nobel (Fapesp), 1999.

ROLNIK, Raquel. Dez anos do Estatuto da Cidade: das lutas pela reforma urbana às cidades da Copa do Mundo. In: RIBEIRO, Ana Clara; VAZ, Lilian V.; SILVA, Maria Lais P. (orgs.). Leituras da cidade. Rio de Janeiro: ANPUR; Letra Capital, 2012.

SANTOS, Milton. A urbanização brasileira. São Paulo: HUCITEC, 1993. 
SILVA, José Afonso da. Direito Urbanístico Brasileiro. São Paulo: Malheiros, 2012.

SILVA, Virgílio Afonso da. Federalismo e articulação de competências no Brasil. In: PETERS, B. Guy; PIERRE, Jon (orgs.) Administração Pública. Coletânea. São Paulo: Unesp, 2010. 